\title{
COMPUTATIONAL ASSESSMENT OF A 3-STAGE AXIAL COMPRESSOR WHICH PROVIDES AIRFLOW TO THE NASA 11- BY 11-FOOT TRANSONIC WIND TUNNEL, INCLUDING DESIGN CHANGES FOR INCREASED PERFORMANCE
}

\author{
Sameer Kulkarni \\ NASA Glenn Research Center \\ Cleveland, Ohio, USA \\ Philip C. Jorgenson \\ NASA Glenn Research Center \\ Cleveland, Ohio, USA
}

\author{
Timothy A. Beach \\ Vantage Partners, LLC \\ Brook Park, Ohio, USA \\ Joseph P. Veres \\ NASA Glenn Research Center \\ Cleveland, Ohio, USA
}

\begin{abstract}
New rotor blades are to be fabricated for the 24 foot diameter, 3-stage axial compressor which provides airflow in the 11- by 11-Foot Transonic Wind Tunnel Facility at NASA Ames Research Center in Moffett Field, California. This presents an opportunity to increase the peak Mach number capability of the tunnel by redesigning the compressor for increased pressure ratio. Simulations of the existing compressor from the APNASA CFD code were compared to performance predictions from the HT0300 turbomachinery design code and to compressor performance data taken during a 1997 facility checkout test. It was found that the existing compressor is operating beyond the stability limits predicted by the analysis tools. Additionally, CFD simulations were sensitive to endwall leakages associated with stator button gaps and under-stator-platform flow recirculation. When stator button leakage and cavity recirculation were modeled, pressure rise at design point increased by over $25 \%$ due to a large reduction in aerodynamic blockage at the hub. After improving the CFD model and validating the tools against test data, a new design is proposed which achieved $10.5 \%$ increased total pressure rise and substantially reduced diffusion factors.
\end{abstract}

\section{INTRODUCTION}

A large 24 foot diameter 3-stage axial compressor powered by variable-speed induction motors provides the airflow in the closed-return 11- by 11-Foot Transonic Wind Tunnel (11-Foot TWT) Facility at NASA Ames Research Center at Moffett Field, California. The facility is part of the Unitary Plan Wind Tunnel which was completed in 1955. The tunnel has been used extensively for development of fixed-wing airframes since the 1960s. The test section is currently capable of Mach number ranging from 0.20 to 1.45 and Reynolds number ranging from 300,000 to $9,600,000$ [1]. Over its history, upgrades to the 11Foot TWT such as flow conditioning devices and additional instrumentation have increased blockage and pressure loss, reducing the peak Mach number capability of the test section. A desire exists to increase the peak Mach number to 1.5 or greater. The compressor operating line and the associated test section Mach number are shown in Figure 1.

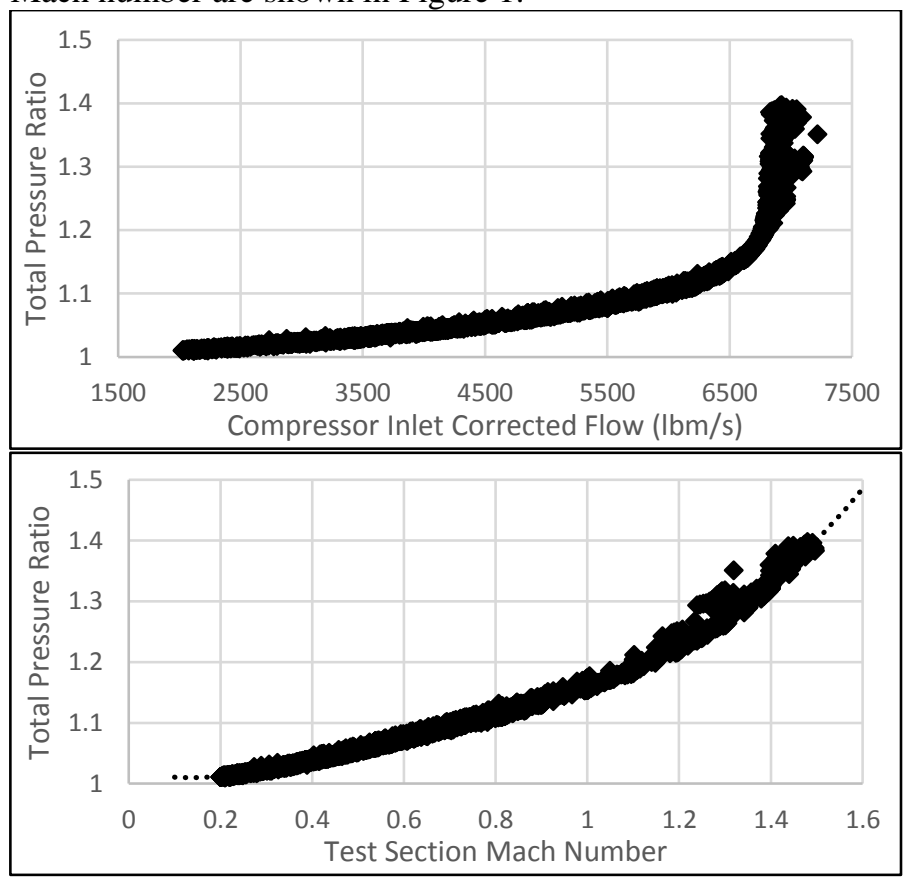

Figure 1: Compressor and facility operating lines. 
The rotor blades of the compressor in this facility are currently made of aluminum due to rotordynamics-related constraints on blade weight. Due to the relatively low strength of aluminum, the blades are inspected in-situ every 50 test hours for cracks and other damage. Furthermore, a major overhaul is performed every 2400 test hours during which the casing is split and the rotor blades are removed for penetrant inspection and sanding/machining. The latter process involves about 1 manyear of effort with an associated facility downtime of 1 month. As of this writing, the aluminum rotor blades are to be replaced with hollow steel rotor blades. This is expected to greatly reduce maintenance and facility downtime associated with blade inspections and overhauls. Replacement of the rotor blades presents an opportunity to increase the Mach number capability of the tunnel by redesigning the compressor for increased pressure ratio. Any new design is challenged by several constraints: use of the existing driveline, rotor disks, stator vanes, and hub and casing flow paths.

The current effort was undertaken to characterize the performance of the existing compressor design using available design tools and computational fluid dynamics (CFD) codes. After that exercise, the learnings were applied to recommend a new compressor design which increases total pressure rise by more than $10 \%$, resulting in increased test section Mach number capability. The APNASA 3D RANS multi-stage turbomachinery CFD code and the HT0300 turbomachinery design code were the primary analysis tools that were used. The ADPAC 3D RANS CFD code with a mixing plane model was also used to analyze under-stator-platform cavity flow to validate assumptions made in the APNASA simulations. The computations were compared to data taken during a 1997 facility checkout test.

\section{NOMENCLATURE}

CFD Computational fluid dynamics

D Diffusion factor

EGV Exit guide vane

IGV Inlet guide vane

P0 Total (stagnation) pressure

R1/2/3 Rotor $1 / 2 / 3$

RPM Physical revolutions per minute

RPMC Revolutions per minute corrected to standard day

$\mathrm{S} 1 / 2 / 3$ Stator $1 / 2 / 3$

TWT Transonic wind tunnel

$\mathrm{V}_{1} \quad$ Axial velocity at blade row inlet plane

$\mathrm{V}_{2} \quad$ Axial velocity at blade row exit plane

$\Delta \mathrm{V}_{\theta} \quad$ Difference in inlet and exit relative tangential velocities $\sigma \quad$ Solidity

\section{COMPRESSOR GEOMETRY, OPERATION, AND DESIGN CONSTRAINTS}

The physical rotational speed of the compressor ranges from 150 to 650 RPM, corresponding with rotor tip speeds of 190 to $815 \mathrm{ft} / \mathrm{s}$. Facility personnel believe that margin is available in the motor, shaft, and bearings to achieve 695 RPM for a new compressor design. At the peak test section Mach number of
1.45 , the compressor inlet Mach number is about 0.4 with inlet corrected mass flow rate of about $7000 \mathrm{lb} / \mathrm{s}$. The hub and casing flow paths have constant radius of $8.5 \mathrm{ft}$ and $12 \mathrm{ft}$ respectively. A desire exists to reuse the existing flow path for any proposed design, driven by schedule and budget constraints.

The existing compressor is an axial turbomachine with NACA 65 series airfoils. A cross-sectional sketch is shown in Figure 2. The compressor consists of a row of 54 inlet guide vanes (IGVs) followed by three rotor-stator stages and a row of 60 exit guide vanes (EGVs). There are 52 rotor blades per stage, 34 vanes in stages 1 and 2, and 58 vanes in stage 3 . The IGV, S3, and EGV have constant chord along the span. Structural support struts upstream of the IGV and downstream of the EGV were neglected in the current analysis. Any new design was constrained to use the same number of blades and vanes since fabrication of new rotor disks and new casing penetrations were outside the scope of this effort. Furthermore, a desire to reduce tooling costs drove a requirement for any new design to have identical blade shapes across all three stages, with an allowance for rotor stagger changes from stage to stage.

The IGVs have variable camber via a mid-chord hinge that allows the aft section to swing open or closed during tunnel operation. The IGV nominal setting of $0^{\circ}$ gives approximately $+33^{\circ}$ of positive pre-swirl into rotor 1 , and the IGV flap can vary from $-7.5^{\circ}$ (less pre-swirl) to $+19.5^{\circ}$ (more pre-swirl). The other stator vanes are on buttons that may be manually reset to change stagger when the facility is shut down, but this is atypical for normal tunnel operation. Any new design is constrained to use the existing stator vanes, but re-staggering S1, S2, S3, and EGV is possible. The IGV must be used as-is due to complexities and cost associated with removing/replacing the IGV actuators. However, it may be possible to close the IGV by an additional $2.5^{\circ}$ for $-10^{\circ}$ total closure from nominal.

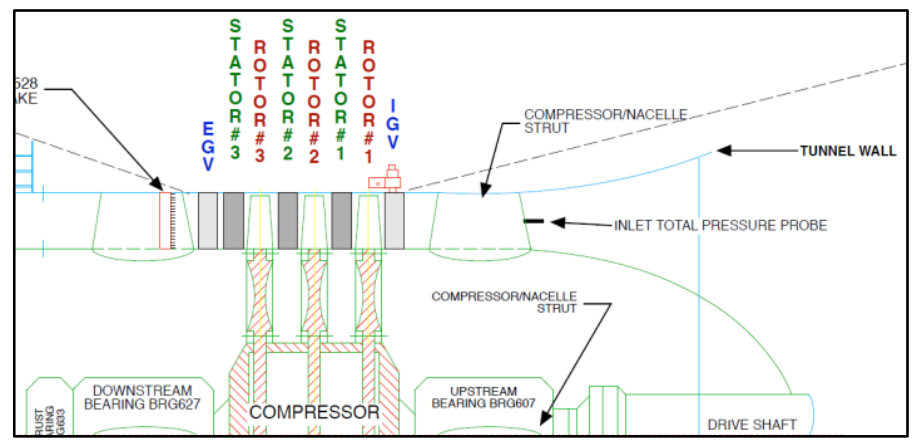

Figure 2: Compressor cross-section (inlet at the right).

The test section Mach number and Reynolds number are set by varying compressor speed, IGV camber, and compressor inlet pressure. The compressor inlet pressure is set via a separate pressurization sub-system and can vary between 3 and 32 psia. A heat exchanger downstream of the compressor exit is used to maintain test section and compressor inlet temperature to $110+/$ $20^{\circ} \mathrm{F}$. 


\section{VALIDATING TOOLS AGAINST EXISTING DATA}

The first objective of the current work was to validate the design code with existing compressor data. To that end, the HT0300 design code was used in analysis mode with the existing compressor geometry given as input to obtain performance information. Operating points from the 634 RPMC speedline with IGV flap at the nominal setting of $0^{\circ}$ were generated by varying the inlet mass flow rate input parameter. Loss and deviation models for the stators were tuned to match test data performance. The compressor flowpath and blade geometry were exported from the HT0300 code to generate meshes for CFD simulations.

Meshes for the APNASA CFD code were generated using MMESH, detailed by Mulac [2] which produces sheared $\mathrm{H}$ meshes for each blade row with common axial and radial coordinates. The grids in the current effort contain 51 radial points, 51 circumferential points (pressure- to suction-surface), and 51 chord-wise points (leading to trailing edge), with 905 total axial points across the computational domain. This is a typical density for APNASA grids. The static rotor tip clearances were measured as 0.5 inches ( $1.2 \%$ of span), and were modeled with 4 radial cells. The tip clearance flow in APNASA is modeled as an orifice flow, with the effect of the vena contracta accounted for by using a discharge coefficient [3].

The APNASA turbomachinery CFD code [4-6] was used to generate speedlines of the existing compressor. A 3-stage APNASA simulation at 634 RPMC was generated using an HT0300 output as an axisymmetric initial condition. The full speedline was generated by changing the exit static pressure boundary condition. The resulting APNASA and HT0300 speedlines are compared to the data in Figure 3. In the figure, open symbols on the CFD characteristic indicate a solution which is highly unsteady and unconverged. Open symbols on the HT0300 characteristic indicate that diffusion factor has exceeded 0.5 somewhere in the solution. This information indicate that the compressor operates at diffusion factors which would indicate that the compressor is highly separated or stalled. Figure 3 additionally indicates that there exists a deficiency in the initial CFD simulation (APNASA A) since the simulations cannot achieve the pressure ratio observed in neither the data nor the HT0300 result.

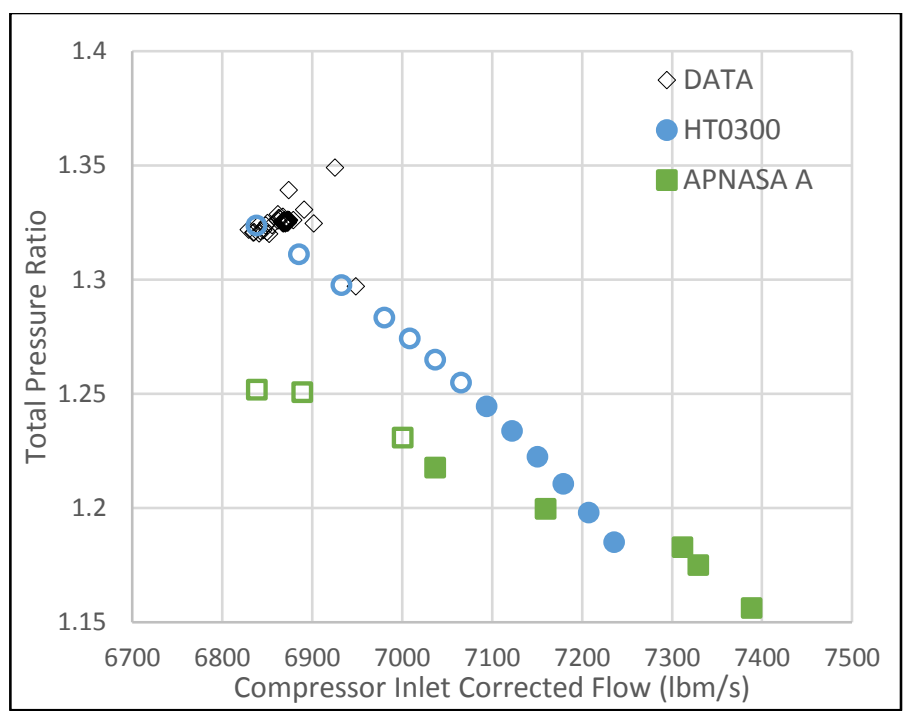

Figure 3: 634 RPMC speedline with nominal IGV angle. Open symbols indicate diffusion factors exceeding 0.5 in the design code or unsteady/unconverged CFD results. "APNASA A" is the baseline CFD simulation.

A spanwise total pressure profile from the CFD was compared to test data from two rakes in Figure 4. The figure highlights the point that the initial CFD model is missing critical flow features. The rakes were positioned $180^{\circ}$ apart (North and South positions) and 1.25 EGV chords downstream of the EGV, measuring 20 total pressures along the span. The CFD profile was circumferentially mass-averaged at the approximate axial location of the rakes. These profiles are at operating points of approximately $6890 \mathrm{lb}_{\mathrm{m}} / \mathrm{s}$ and are normalized by the inlet total pressure upstream of the IGV. Even after accounting for the lower level of pressure in the CFD relative to data, it appears that a full $50 \%$ of span in the CFD is separated, unlike the profiles from the data which indicate some weakness in the pressure profile extending up to only $20 \%$ span on the South Rake and up to $30 \%$ span on the North Rake.

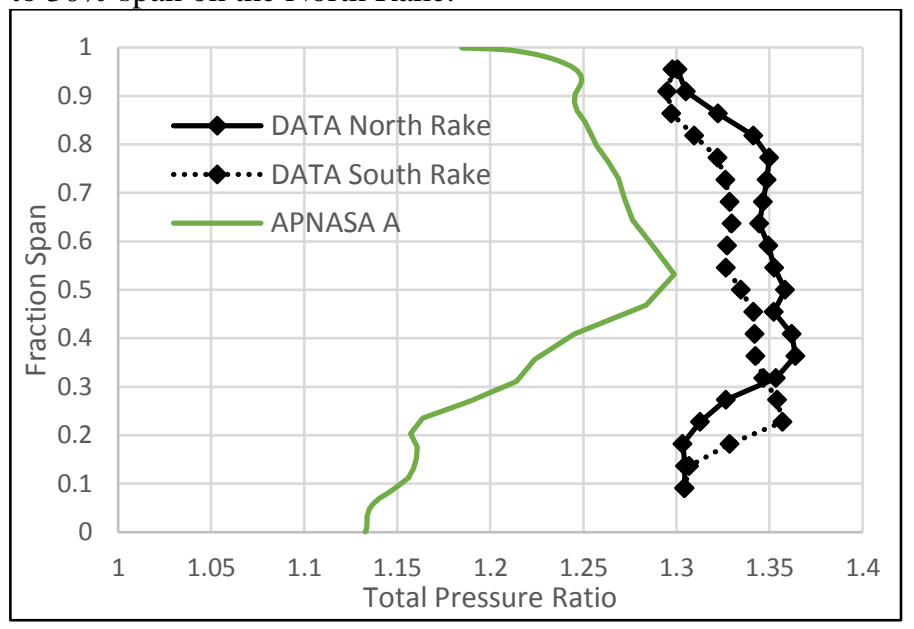

Figure 4: Radial profile of exit P0 normalized by inlet PO. 
A meridional view of the flow domain with circumferentially mass-averaged axial velocity is shown in Figure 5, which confirms large scale hub separation exists in this baseline CFD case. The separation begins at the hub near the trailing edge of R2, and rapidly expands in the radial direction through S2, with the low momentum region persisting on through the rest of the compressor and into the exit plane.

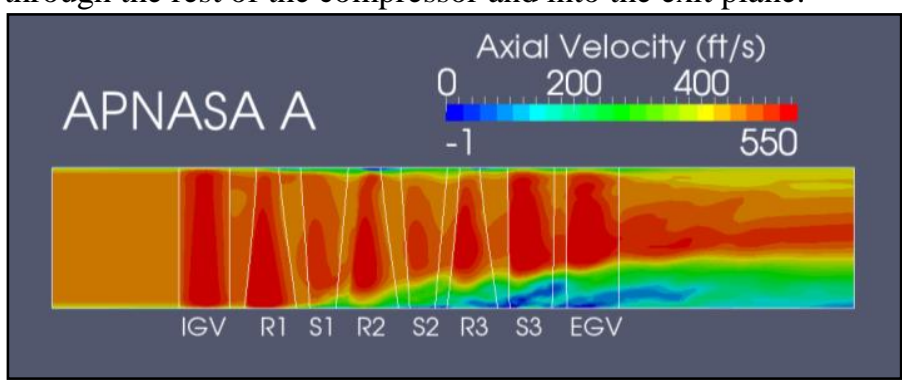

Figure 5: Circumferentially mass-averaged axial velocity contour of the initial CFD result showing massive hub separation.

To address this difference between CFD and data, the compressor hardware was examined for physical/geometrical features that were not included in the initial CFD simulations. This examination was done during a rotor blade overhaul while the case halves were split. Two features were identified: (1) endwall gaps associated with stator buttons, and (2) axial gaps at the hub of $0.25-0.5$ inches permitting flow through unsealed under-stator-platform cavities beneath the $\mathrm{S} 1$ and $\mathrm{S} 2$ hub shrouds as shown in Figure 6.

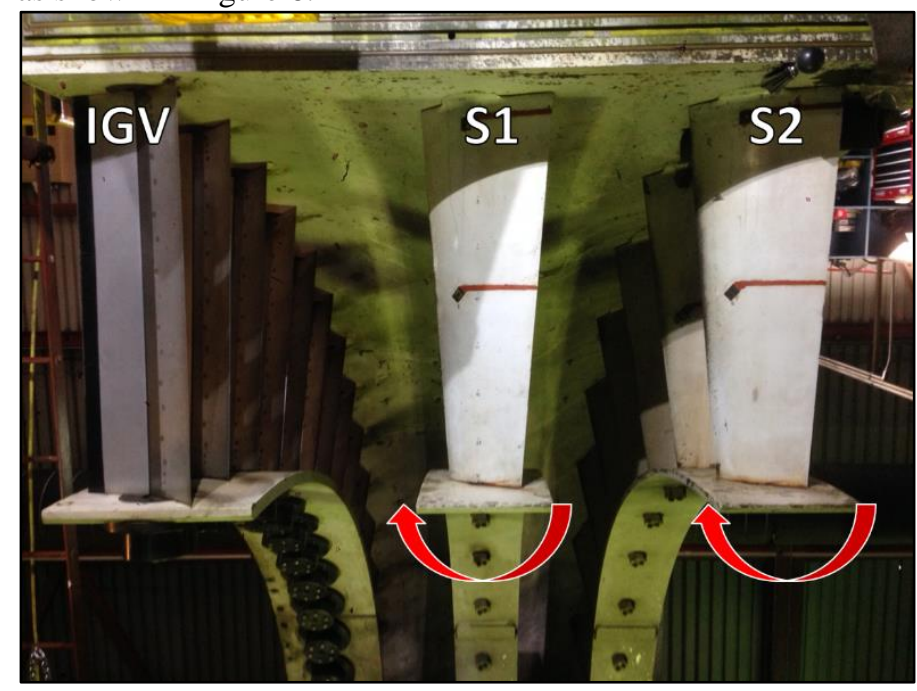

Figure 6: Photograph of casing and stator rings (rotors not pictured) showing direction of flow recirculation through the unsealed under-stator cavities.

\section{EFFECT OF STATOR BUTTON LEAKAGE AND UNDER- STATOR-PLATFORM RECIRCULATION}

In two separate studies, the initial APNASA simulation is updated to include (1) the button gap leakages at the S1, S2, S3, and EGV endwalls, and (2) the under-stator-platform leakages about $\mathrm{S} 1$ and $\mathrm{S} 2$.
The gap associated with the stator button was modeled in a new APNASA simulation (APNASA B - "Button leakages"). Gaps of 0.5 inch at hub and casing were modeled for S1, S2, S3, and EGV as periodic boundary conditions. The size of the modeled gap was an approximation to reduce meshing complexities. The physical gaps are approximately half of the 0.5 inches modeled in the current effort. The recommendation is to refine the model to more accurately reflect the physical gap sizes but this exercise is left for future work. At the hub, the gap spanned from leading edge to $44 \%$ chord and from $56 \%$ chord to trailing edge. At the casing, the gap spanned from leading edge to $14 \%$ chord, and from $61 \%$ chord to trailing edge.

The under-stator-platform leakages about S1 and S2 were modeled in a separate APNASA simulation (APNASA C "Cavity leakages") as axisymmetric mass flux boundary conditions at the hub, where $2 \%$ of inlet physical mass flow rate was bled downstream of the stator, and re-injected upstream of the leading edge at a radial angle of $30^{\circ}$ from the hub, and with a tangential velocity component equal to $50 \%$ of the wheel speed. The recirculated mass flow rate was a rough estimate based on the static pressure gradient at the hub and the gap size of about 0.75 inches, and the reinjection flow angle was an estimate based on prior experience.

The characteristics from these new simulations are compared to data and the initial simulation (APNASA A) in Figure 7. Inclusion of either the stator button gaps or the cavity recirculation had the effect of increasing the overall total pressure rise of the compressor by about $25 \%$. The cavity leakages at the hub had an additional effect of increasing stability of the CFD result, unlike the result with button leakages, which still exhibited unsteadiness as observed in the baseline APNASA cases at low flow rates. However, these new simulations could only be throttled to about $6935 \mathrm{lb}_{\mathrm{m}} / \mathrm{s}$ inlet corrected flow rate before the rapid onset of numerical stall.

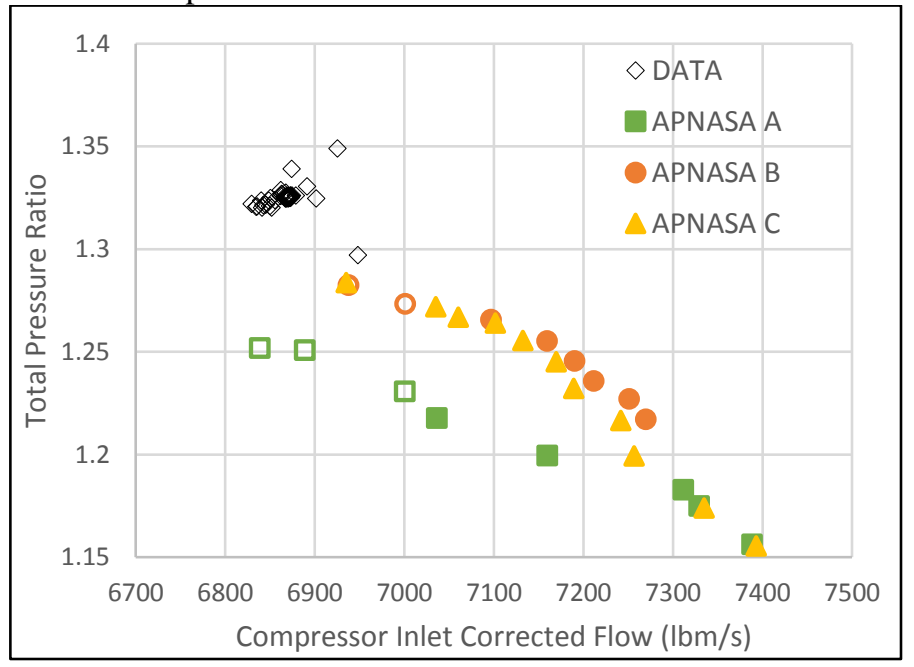

Figure 7: 634 RPMC speedline with nominal IGV angle. Open symbols indicate diffusion factors exceeding 0.5 in the design code or unsteady/unconverged CFD results. "APNASA A" is the baseline CFD simulation. "APNASA B" is a case modeling stator button gaps. "APNASA C" is a case modeling under-stator cavity flow recirculation. 
The exit total pressure profiles from the lowest flow rate cases of these new simulations are compared to the rake data and the baseline CFD result in Figure 8. From 50\% span to the casing, the profiles of the baseline APNASA A case and the cavity recirculation APNASA C case are nearly identical. This is expected as no changes were instituted in the modelling of the flow at the casing. The APNASA B case has somewhat strengthened the pressure profile between $70 \%$ and $95 \%$ span compared to the other CFD cases. This difference is likely attributable to modelling of the stator button gaps at the casing. Despite noting that the level of pressure of the CFD results remains lower than the data, the stator button gaps and cavity recirculation have both had the effect of strengthening the flow below 50\% span. Case APNASA C with hub cavity recirculation had a stronger hub profile than case APNASA B. The shapes of the new cases APNASA B and C both agree better with data than the baseline APNASA A case.

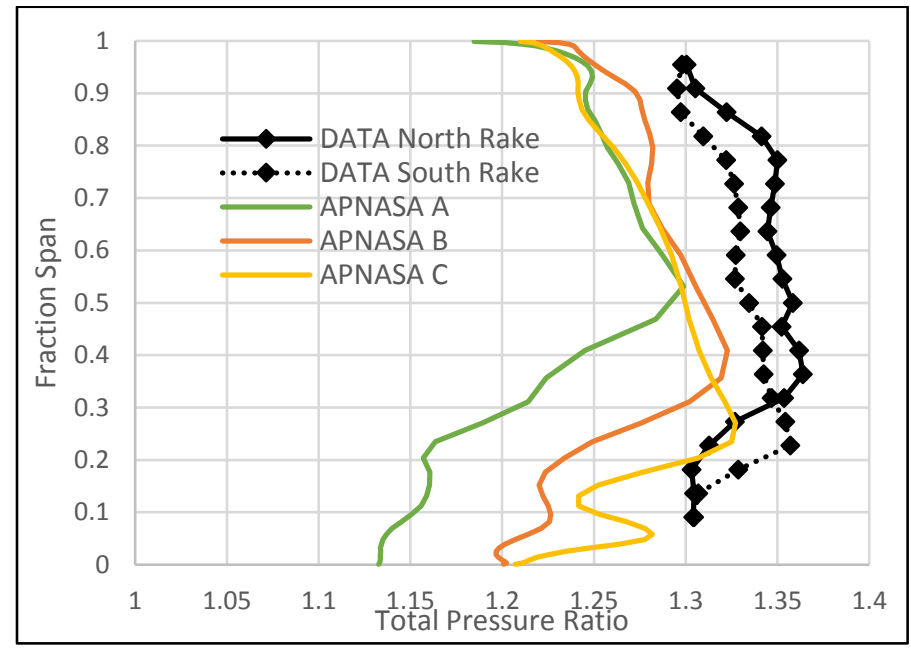

Figure 8: Radial profile of exit $P 0$ normalized by inlet $P 0$.

APNASA $B$ and $C$ show stronger hub profiles and better match with test data.

Meridional views of the flow domain with circumferentially mass-averaged axial velocity for the cases with stator button gaps and with hub cavity recirculation are shown in Figure 9. These figures confirm that the low momentum, separated flow at the hub shown in Figure 5 from the baseline case APNASA A is significantly reduced in these new cases, especially so in APNASA C.
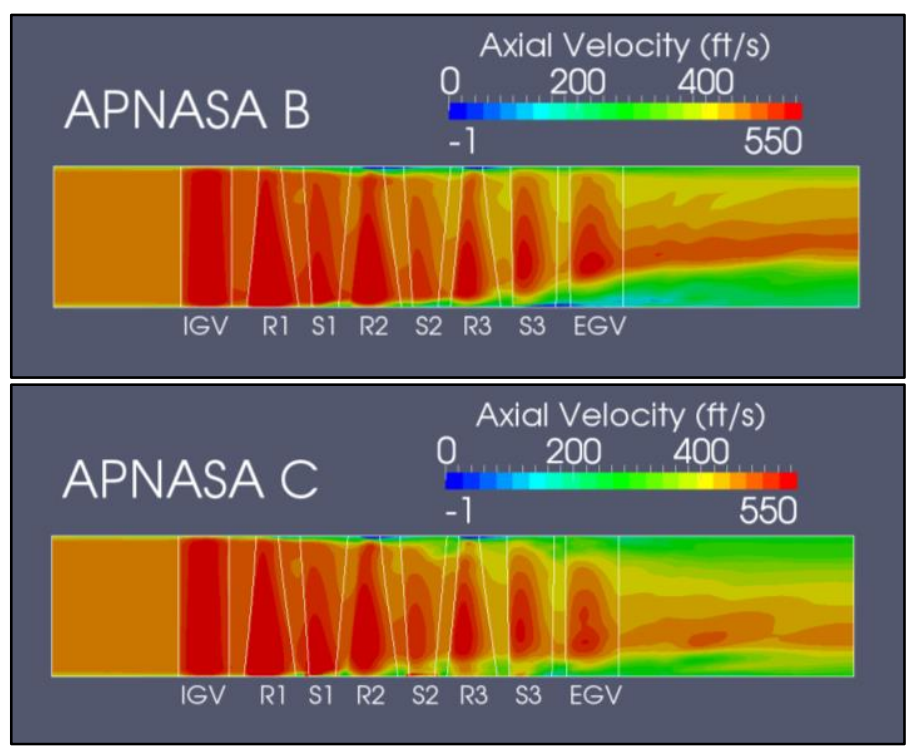

Figure 9: Circumferentially mass-averaged axial velocity contour of cases APNASA B and C showing reduced hub separation.

Figure 10 shows a cross-passage plane at about $70 \%$ chord of the $\mathrm{S} 3$ vane passage from each of the three APNASA cases A, $\mathrm{B}$, and $\mathrm{C}$. We see from APNASA A that this is a region where a large corner separation begins to form at the hub off of the suction surface, as well as a smaller corner separation at the casing from the suction surface. The hub and casing corner separations are greatly reduced in case B due to the stator button gap allowing flow to pass under/above the stator from the pressure surface, which re-energizes the low momentum fluid forming on the suction surface. The hub corner separation is also greatly reduced in case $\mathrm{C}$, but this is mainly due to the smaller hub boundary layer driven by the higher momentum fluid being injected upstream of the S1 leading edge from the under-stator cavity.

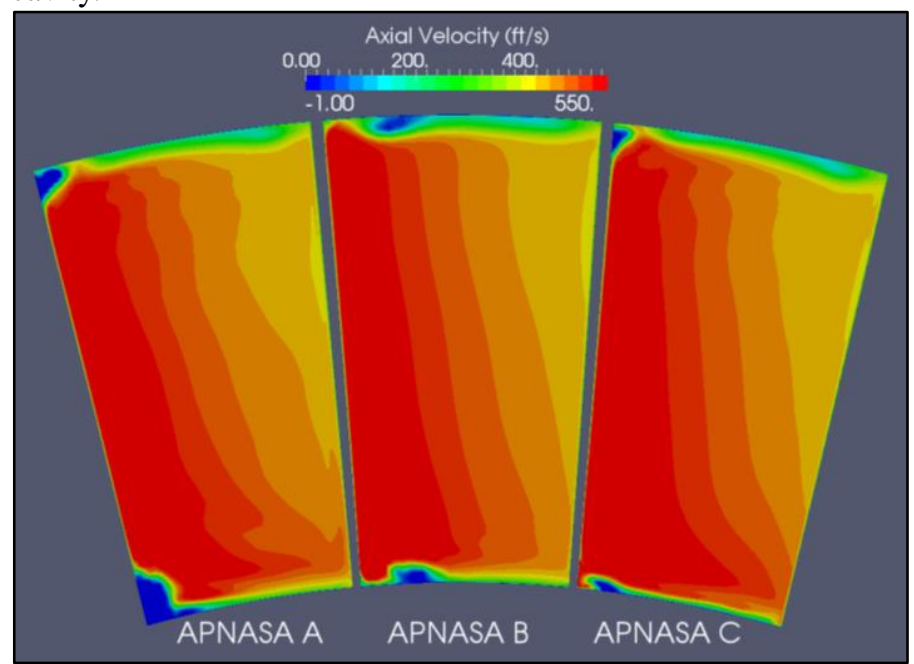

Figure 10: Cross-passage contours of axial velocity at $70 \%$ chord of stator 3. Left passage is baseline case, middle passage is stator button gap case, and right passage is under-stator cavity flow case. Hub corner separation at the suction surface is reduced in the latter two cases. 
The unexpected beneficial results seen in APNASA C led to a deeper investigation of the assumptions made for recirculated mass flow rate of $2 \%$ of inlet physical flow and injection angle of $30^{\circ}$ from the hub. A desire to grid the under-stator-platform cavities led to the use of the ADPAC code [7] due to its multipleblock grid capability and its adaptability to use the existing APNASA grids. Mixing plane interfaces between rotating and stationary blade rows were used. All three compressor stages were simulated in the ADPAC analysis, but only a single operating point was generated. Grids for the under-statorplatform cavities beneath $\mathrm{S} 1$ and $\mathrm{S} 2$ generated, and interface planes were tied to the existing APNASA blade row grids as shown in Figure 11, allowing the mass flow rate through the cavity to be driven directly by the static pressure gradient across the stator.

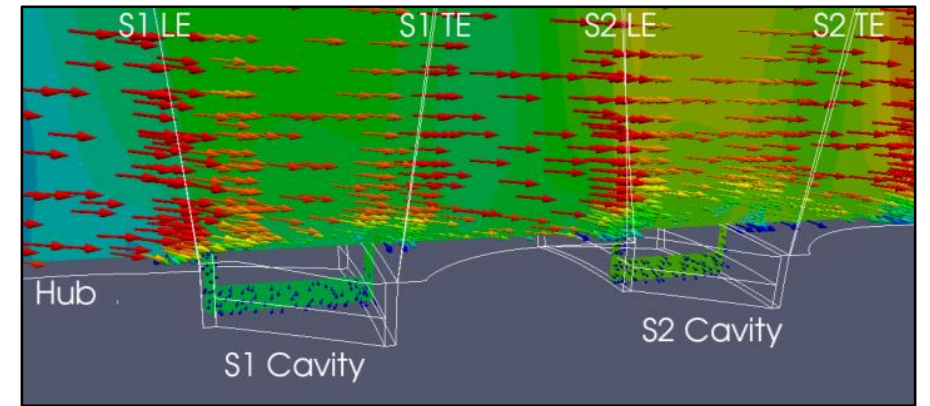

Figure 11: Meridional contour of static pressure showing the under-stator cavity flow recirculation, with absolute velocity vectors colored by axial velocity magnitude.

A single operating point at 634 RPMC was simulated. The flow recirculation associated with the unsealed under-stator cavities under was about $0.5 \%$ of the inlet physical mass flow rate, which was about 4 times smaller than the assumption made in the APNASA model. This was true for both S1 and S2 cavities. The injection angles measured from the hub upstream of S1 and S2 were about $25^{\circ}$ and $20^{\circ}$, respectively. The injection angle of $30^{\circ}$ was a reasonable assumption in APNASA. Applying these learnings, an APNASA simulation with best efforts at modeling the physical features of the existing compressor was generated. This simulation included models both for stator button gaps and bleed and injection at $30^{\circ}$ from the hub associated with understator cavities which recirculated $0.5 \%$ of inlet physical flow. This result, referred to as APNASA *, is compared to the baseline APNASA A case and to the data in Figure 12. The operating point at $6800 \mathrm{lb} / \mathrm{s}$ is unsteady and near-stall. The characteristic is improved in the APNASA * case to match or exceed the performance predicted by the HT0300 code, but the level of pressure is still lower than the data at low flow rates, and throttling the simulation to those lower flow rates remains challenging.

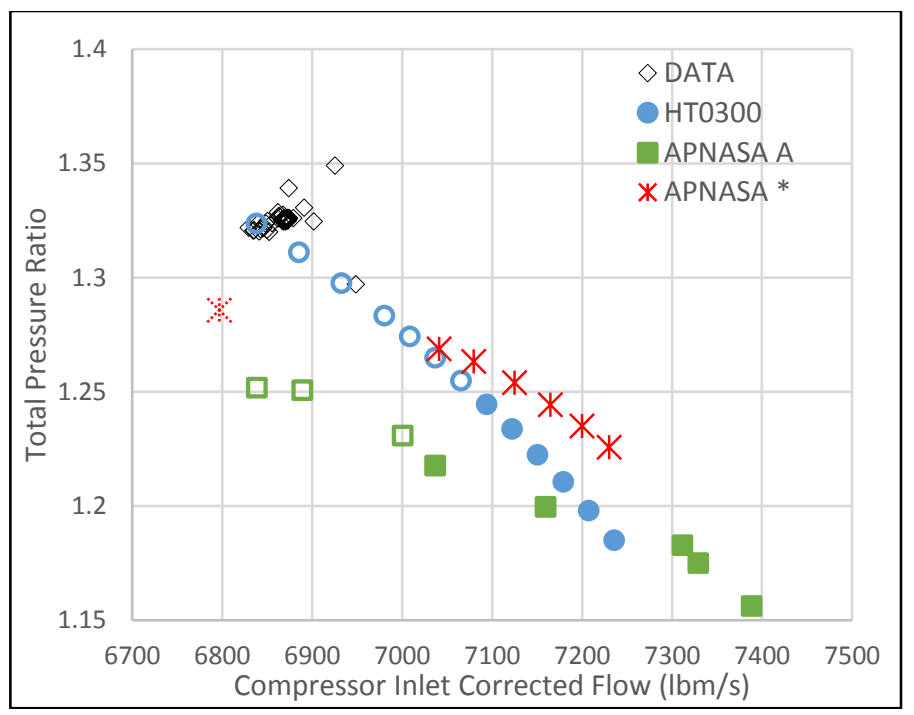

Figure 12: 634 RPMC speedline with nominal IGV angle. Open symbols indicate diffusion factors exceeding 0.5 in the design code or unsteady/unconverged CFD results. "APNASA A" is the baseline CFD simulation. "APNASA *" is the case with stator button gaps and under-stator cavity flows modeled.

The exit total pressure profile from the lowest converged flow rate APNASA * case is compared to the data in Figure 13 to ascertain whether the critical flow phenomena are being captured after expanding the model to include stator button gaps and under-stator cavity flows. The profiles are now normalized by their maximum values to separate the offset in level of pressure from the shapes of the profiles. There is good agreement between the APNASA * case and the data in terms of profile shape.

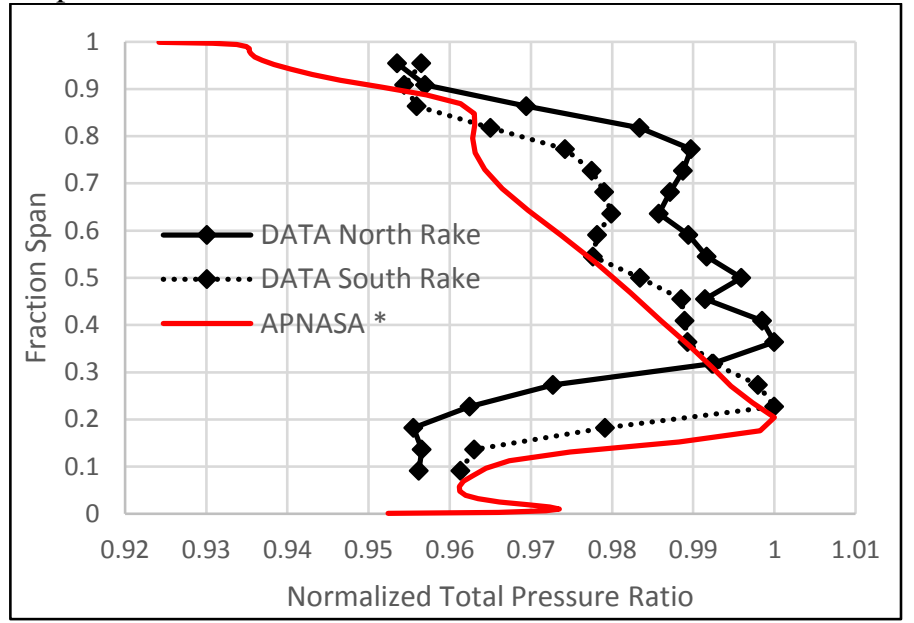

Figure 13: Radial profile of exit pressure ratio, normalized by the local maximum exit pressure ratio. APNASA * shows good agreement with rake data in profile shape.

\section{DIFFUSION FACTOR LIMITATIONS RECOMMENDATIONS FOR A NEW DESIGN}

AND

The question of why the CFD does not match the level of total pressure remains open, but hypotheses can be made after 
examining spanwise profiles of S3 diffusion factor from HT0300 at a range of operating points, as shown in Figure 14. The diffusion factor predicted by HT0300 exceeds 0.5 at the S3 hub for flow rates lower than $7040 \mathrm{lb}_{\mathrm{m}} / \mathrm{s}$. The other stators have lower levels of diffusion factor than S3 across the speedline. The diffusion factor for a compressor blade element is defined as [8]:

$$
D=\left(1-\frac{V_{2}}{V_{1}}\right)+\frac{\Delta V_{\theta}}{2 \sigma V_{1}}
$$

As the compressor is throttled to lower flows, loading and diffusion factor are increased. In the real machine, the compressor may be able to continue operating at these lower flow rates while enduring a rotating stall instability triggered by a hub separation in S3. However, a large separation in the steady RANS CFD simulation eventually results in a flow instability that leads to numerical stall.

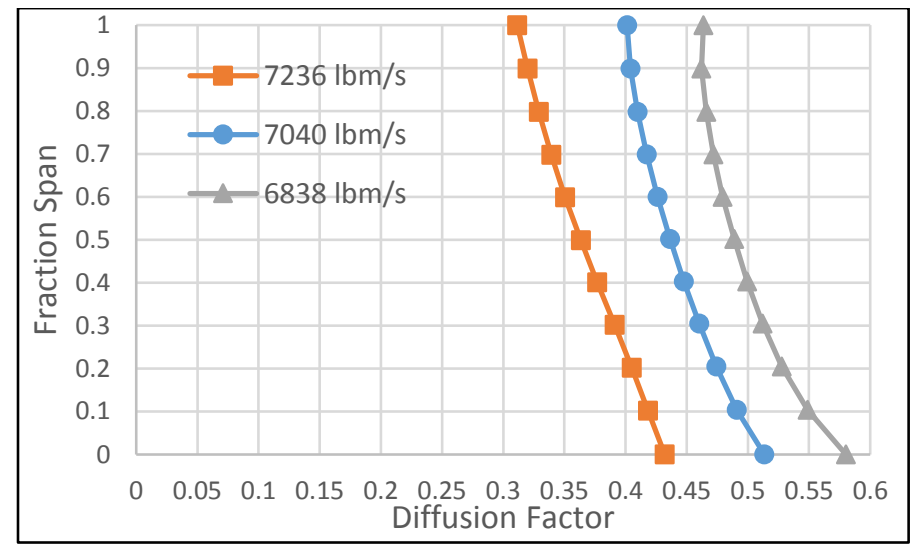

Figure 14: Stator 3 diffusion factor predicted by HT0300 for a range of operating points with nominal IGV angle at 634 RPMC

The diffusion factors are high at the nominal $0^{\circ} \mathrm{IGV}$ flap setting, as shown above. Simulation of the compressor at peak pressure ratio with IGV flap at $-7.5^{\circ}$ was more problematic as the diffusion factors increase further. This was evident as shown in Figure 15 showing the total pressure characteristic for the case with IGV flap set to $-7.5^{\circ}$. Diffusion factors exceed 0.5 at the S3 hub for flows lower than $7350 \mathrm{lb} / \mathrm{s}$ inlet corrected flow. The numerical stall limit of the CFD occurs at a slightly lower flow rate of $7250 \mathrm{lb} / \mathrm{s}$. The compressor data indicates that the machine operates between 6830 and $7100 \mathrm{lb} / \mathrm{s}$. Again, it is hypothesized that the actual compressor is operating in a highly unstable range at these conditions. The CFD indicates large scale separation at the hub as the compressor is throttled to low flow operating points. This is likely attributable to the constant area flow path as well as the low solidity of the stators, which causes high diffusion factors at the hub.

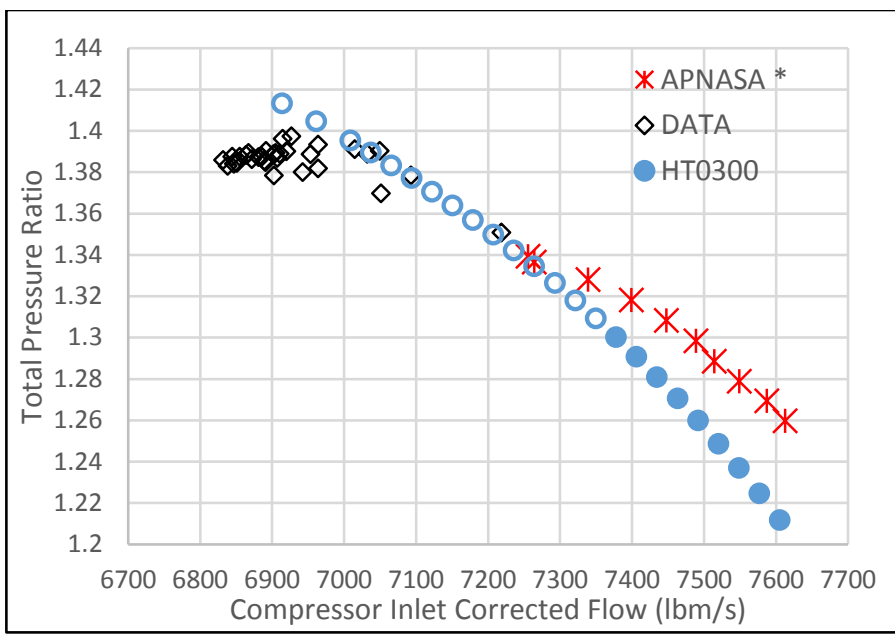

Figure 15: 634 RPMC speedline with $-7.5^{\circ}$ IGV angle. Open symbols indicate diffusion factors exceeding 0.5 in the design code.

In order to obtain credible predictions with the analysis tools for a new design with a goal of increasing total pressure ratio, the high diffusion factors at the S3 hub must be mitigated. With constraints on changes to the shape and number of stator airfoils and flow path, increasing solidity to reduce the diffusion factor is difficult. To satisfy the requirement for increased pressure ratio, it was necessary to break the constraint requiring use of existing S3 and EGV airfoils. If new S3 and EGV blade geometry can be specified, the turning can be split more evenly between the two tandem stator rows, reducing the exceedingly high S3 diffusion factor. Additionally, if new S3 and EGV vanes are fabricated, it is possible to increase the hub radius to reduce area and further reduce diffusion factor.

\section{PERFORMANCE PREDICTIONS OF A PROPOSED REDESIGN}

A proposed redesign of the compressor was developed. The new design utilizes the existing IGV. The nominal speed was increased from 650 RPM to 690 RPM. The rotor blade inlet and exit metal angles were modified to accommodate changes in incidence associated with the higher rotational speed. NACA 65 series airfoils were used, as in the existing design. Identical rotor blade shapes were used for all three stages to reduce manufacturing and tooling costs. The stage 3 rotor was staggered $2^{\circ}$ closed to reduce incidence. The new design re-staggered the existing $\mathrm{S} 1$ and $\mathrm{S} 2$ to reduce incidence angles at the increased nominal speed. New airfoil shapes for S3 and the EGV were proposed which incorporated an increase in the hub radius from $8.5 \mathrm{ft}$ to $9.4 \mathrm{ft}$. Additionally, the $\mathrm{S} 3$ chord was increased by $15 \%$ at the casing and $21.5 \%$ at the hub, increasing solidity by about $14 \%$ averaged across the span.

Predictions of this proposed design were generated with both HT0300 and APNASA, with models for stator button gaps and under-stator cavity flows in the CFD. At the highest pressure ratio conditions associated with $-7.5^{\circ} \mathrm{IGV}$ flap angle, the speedline of the redesigned compressor is compared to the performance of the existing compressor in Figure 16. The 
redesigned geometry throttles to lower flow rates in the CFD simulation. Comparing the HT0300 results at $7000 \mathrm{lb} / \mathrm{s}$, the total pressure rise is increased by $10.5 \%$ in the proposed redesign. The CFD and HT0300 agree well in terms of the relative increase in total pressure ratio from the existing design.

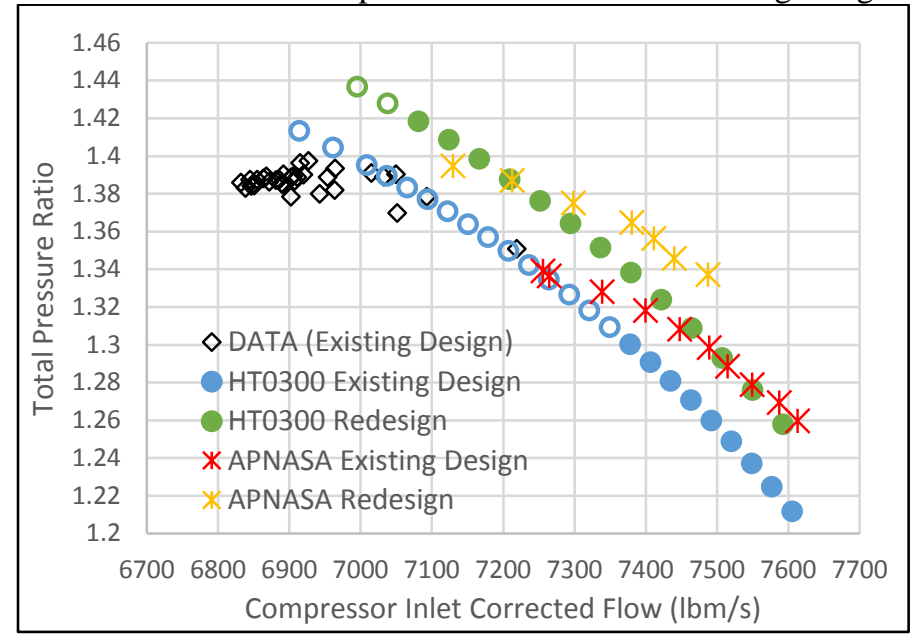

Figure 16: Speedlines with $\mathbf{- 7 . 5 ^ { \circ }}$ IGV angle. Open symbols indicate diffusion factors exceeding 0.5 in the design code. Existing design results are at 634 RPMC and redesign results are at 653 RPMC.

The CFD simulations which not able to reach converged results at flows below $7250 \mathrm{lb}_{\mathrm{m}} / \mathrm{s}$ in the original design, but in the redesign, steady results with flow rates of $7100 \mathrm{lb} / \mathrm{s}$ were achieved. This is because the S3 diffusion factor has been greatly reduced in the new design at comparable mass flow rates. This was balanced with a slight increase in the EGV loading. A comparison of S3 and EGV spanwise diffusion factors at a flow rate of about $7250 \mathrm{lb} / \mathrm{s}$ for the existing design and the redesign is shown in Figure 17. The CFD result indicates higher diffusion factors at the hub compared to the prediction from the design code, but these results indicate a reduction in $\mathrm{S} 3$ diffusion factor of approximately $50 \%$ relative to the existing design.

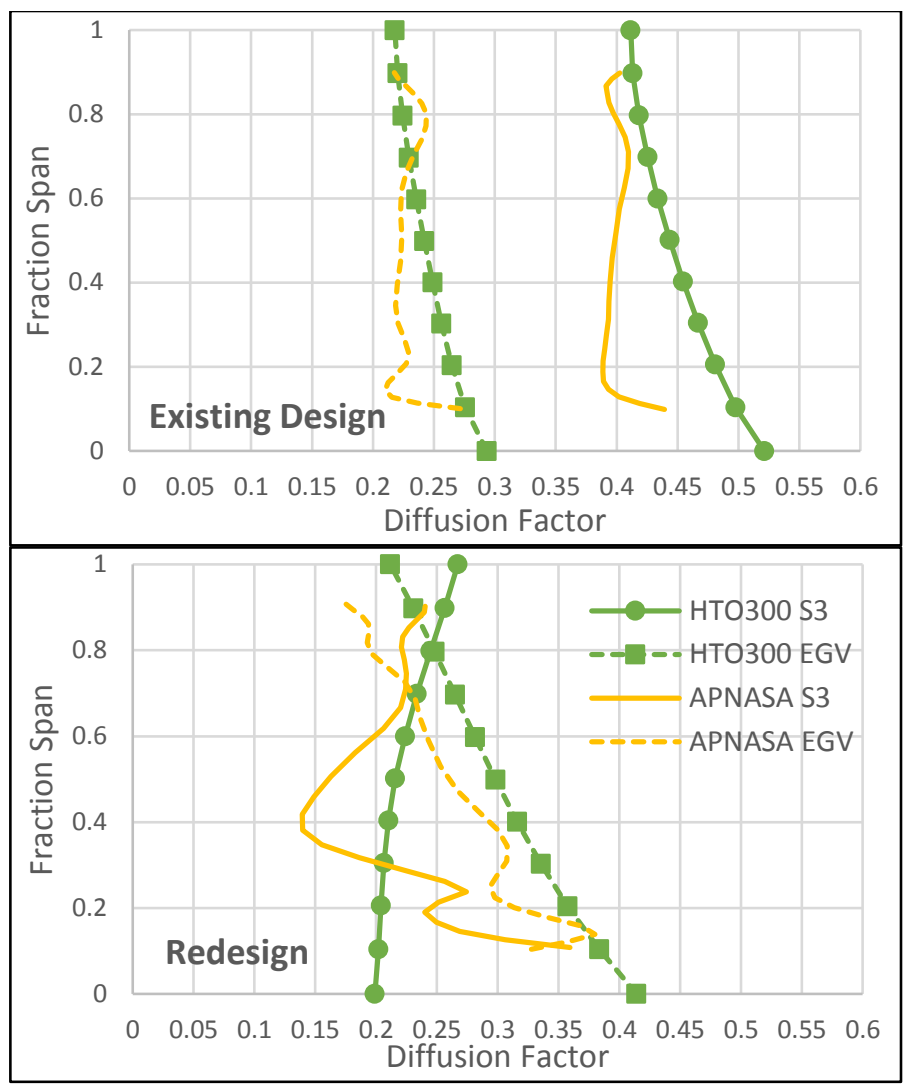

Figure 17: Stator 3 and EGV diffusion factor with $-7.5^{\circ}$ IGV angle and $7250 \mathrm{lbm} / \mathrm{s}$ for the existing design (top) at $634 \mathrm{RPMC}$ and redesign (bottom) at $653 \mathrm{RPMC}$

Figure 18 shows the APNASA circumferentially mass-averaged axial velocity of the new design at $7250 \mathrm{lb} / \mathrm{m}$. Although there is evidence of hub separation in the $\mathrm{S} 1$ and $\mathrm{S} 2$ passages due to the increases in speed and overall pressure ratio, the spanwise extent of the low momentum region has been significantly reduced at the compressor exit. The result indicates that further work should focus on reducing the hub separation in S1 and S2. Nevertheless, the current comparison of the CFD result with the design code prediction indicates that the goal of increasing pressure rise by at least $10 \%$ is achievable.

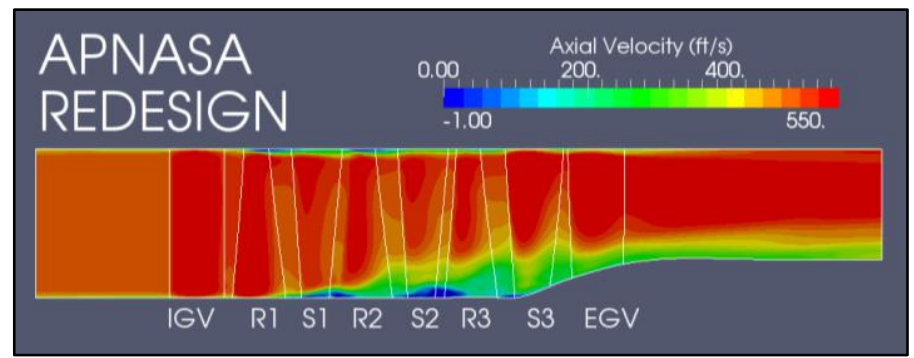

Figure 18: Circumferentially mass-averaged axial velocity contour of the new design showing increased hub radius and S3 chord and reduced hub separation at the compressor exit. 


\section{CONCLUSIONS}

The major conclusions can be summarized as follows:

1. Modeling of endwall leakages in the stators associated with the button gaps was critical in matching exit total pressure profile shape from test data. Inclusion of these gaps resulted in $27 \%$ increased total pressure rise compared to the case without stator button gaps. The physical mechanism behind this result is the reduction of corner separation at the hub on the stator's suction surface by higher momentum flow passing from pressure side to suction side across the gap at the hub.

2. Modeling of under-stator flow recirculation about stators 1 and 2 had similar impact of reducing hub corner separation if $2 \%$ of inlet physical flow rate is recirculated about each stator, with $30^{\circ}$ injection angle from the hub. However, a simulation which gridded the under-stator gap revealed that $0.5 \%$ of inlet physical flow rate was a more realistic value.

3. Diffusion factors at $\mathrm{S} 3$ hub were exceeding 0.5 in the existing design. The compressor is likely operating with large scale separations and near or beyond its stability limit. If increased total pressure goals are to be met, the diffusion factor must be reduced in any proposed redesign.

4. The goal of increasing total pressure by greater than $10 \%$ was shown to be achievable by increasing nominal rotational speed, redesigning rotor blades, and restaggering stators to reduce incidence. The redesign reduced $\mathrm{S} 3$ diffusion factor by increasing hub radius through S3 and EGV, increasing S3 chord, and redesigning the S3 and EGV airfoil shapes to split loading distributions.

\section{FUTURE WORK}

Additional CFD analysis is planned to iterate on the redesign and to corroborate the results of the design code. The aerodynamic design will be delivered to 11-Foot TWT personnel for mechanical design and structural analysis. Further aerodynamic design iterations may be necessary e.g. blade thickness distributions.

\section{ACKNOWLEDGMENTS}

The authors thank Mr. Richard Hearsey for his assistance and guidance in using his HT0300 design code and Mr. Daniel Kalcic of NASA Ames Research Center for his efforts as the project manager and central point of contact for this work. The authors also gratefully acknowledge and thank the staff of the NASA Ames 11-Foot TWT for access to their data and for permission to publish it in this paper. The authors additionally thank Dr. Mark Celestina and Dr. Michael Hathaway from NASA Glenn Research Center and Dr. Ali Ameri from the Ohio State University for many beneficial technical discussions, and Mr. Richard Mulac from the University of Toledo for assistance with mesh generation.

\section{REFERENCES}

[1] NASA Ames Research Center, "Unitary Plan Wind Tunnel 11-by 11-foot Transonic Test Section," 13 February 2014. http://www.nasa.gov/content/unitary-plan-wind-tunnel-11by-11-foot-transonic-test-section/.

[2] Mulac, R.A., "A Multistage Mesh Generator for Solving the Average-Passage Equation System," NASA CR-179539, 1988.

[3] Suder, K. L. and Celestina, M. L. "Experimental and Computational Investigation of the Tip Clearance Flow in a Transonic Axial Compressor Rotor.” NASA TM-106711, 1994.

[4] Adamczyk, J. J., Mulac, R. A. and Celestina, M. L., "A Model for Closing the Inviscid Form of the Average Passage Equation System," NASA TM-87199, 1986.

[5] Adamczyk, J. J., "Model Equation for Simulating Flows in Multistage Turbomachinery," NASA TM-86869, 1985.

[6] Adamczyk, J. J., Celestina, M. L., Beach, T. A. and Barnett, M., "Simulation of 3-D Viscous Flow within a Multi-stage Turbomachine," NASA TM-101376, 1989.

[7] Hall, E. J., Heidegger, N. J. and Delaney, R. A., "ADPAC v I .O - User's Manual," NASA CR-1999-206600, 1999.

[8] Lieblein, S., Schwenk, F. C. and Boderick, R. L., "Diffusion Factor for Estimating Losses and Limiting Blade Loadings in Axial-Flow Compressor Blade Elements," NACA RM E53D01, 1953. 
THIS PAGE INTENTIONALLY LEFT BLANK 